\title{
Active and reactive power management of grid connected photovoltaic system
}

\author{
Ameerul A. J. Jeman ${ }^{1}$, Naeem M S Hannoon ${ }^{2}$, Nabil Hidayat ${ }^{3}$, Mohamed M. H. Adam ${ }^{4}$, \\ Ismail Musirin ${ }^{5}$, Vijayakumar. $\mathrm{V}^{6}$ \\ 1,2,3,4,5 Faculty of Electrical Engineering, Universiti Teknologi MARA (UITM), Malaysia \\ ${ }^{6}$ School of Computing Science and Engineering, VIT University Chennai, India
}

\begin{tabular}{l} 
Article Info \\
\hline Article history: \\
Received Sep 14, 2018 \\
Revised Nov 1, 2018 \\
Accepted Nov 12, 2018 \\
\hline
\end{tabular}

\section{Keywords:}

Active power

Non linear control

Photovoltaic system

Reactive power

Voltage source converter

\begin{abstract}
Voltage-source converter (VSC) topology is widely used for grid interfacing of distributed generation (DG) systems such as the photovoltaic system (PV). Since the operation of the VSC is essential to ensure quality of active and reactive power injected to the grid, a control approach is needed to deal with the uncertainties in the grid such as faults. This paper presents a non-linear controller design for a three-phase voltage source converter (VSC). The dynamic variables adopted for the VSC are the instantaneous real and reactive power components. The control approach that interface the VSC between the PV system and the grid are subjected to the current-voltage based. PV system injects active power to the grid and local load while utility grid monitors the power compensation of load reactive power. The proposed non-linear control strategy is implemented for the VSC to ensure fast error tracking and finite convergence time. The adaptive nature of the proposed non-linear control provides more robustness, less sluggish fault recovery compared to conventional PI control. The comprehensive numerical model is demonstrated in MATLAB script environment with power system disturbances such as faults in the grid. The simulation of proposed system is being carried out in MATLAB/SIMULINK environment to validate the control scheme. The proposed control system regulates the VSC ac side real and reactive power component and the dc side voltage.
\end{abstract}

Copyright $(2019$ Institute of Advanced Engineering and Science. All rights reserved.

\section{Corresponding Author:}

Naeem M S Hannoon

Faculty of Electrical Engineering, Universiti Teknologi MARA (UiTM), 40450 Shah Alam, Selangor, Malaysia. Email: hannoon.naeem@gmail.com

\section{INTRODUCTION}

The voltage source converter (VSC) topology is widely accepted for application in electric power generation, transmission and distribution systems [1], [2]. VSC is capable to decouple the instantaneous real and reactive power control in which both components are controlled through the VSC instantaneous qd current components which is proportional to the real and reactive power components. Converting abc currents to current dq components requires a phase-loop loop (PLL) system to determine the phase angle in the dq of the round frame. If PLL dynamics are ignored in the VSC control design, the control system must be strong enough to compensate for the unknown PLL dynamics. In addition, using the current components dq as a dynamic variable leads to a non-linear VSC control model, which in turn adds complexity to the control design. Numerous nonlinear and nonlinear control methods have been proposed in technical publications [3], [4].

Among linear control methods, feedback-based methods do not necessarily provide strong controls, as control provisions (such as margins of stability) are not summarized in this methods [5]. It proposes a root site analysis approach to ensure the power of a controller designed on the basis of feedback from the country. 
Another disadvantage is that such PI-controllers are often designed based on experiments and errors. Among nonlinear methods of regulation, linear feedback methods are not robust because they require a careful correction of nonlinear VSC models. In this context, integrated controls are introduced to eliminate static errors and idle controls to increase the linear control capability of the VSC on [6] and respectively.

This paper presents a new model for strong control design in VSC. The proposed model uses real and immediate interactive power components $(\mathrm{p}) \mathrm{t}$ and $\mathrm{q}(\mathrm{t})$, compared to the current component of conventional $\mathrm{dq}$, as a dynamic variable. $\mathrm{p}(\mathrm{t})$ and $\mathrm{q}(\mathrm{t})$, other than other electrical parameters, have a separate waveform independent of the approved reference frame. Therefore, the values of $\mathrm{p}(\mathrm{t})$ and $\mathrm{q}(\mathrm{t})$ can be specified within the abc reference frame, which is independent of PLL, and is used as a reference to dq to reduce uncertainty in the form. The design of a strong organizational design model is due to dynamic variables, $\mathrm{p}(\mathrm{t})$ and $\mathrm{q}(\mathrm{t})$, not based on the frame of reference. The limits of the proposed approach, based on $\mathrm{p}(\mathrm{t})$ and $\mathrm{q}(\mathrm{t})$ as variables, do not provide excessive capacity at present beyond the limits.

The transformer discussed in this paper is the three-phase DC power source transformer using PWM shaping technology. Traditionally, in the VSC model, the active and reactive power at the PCC is controlled by controlling the direct and quadrature current axis components of the current. This is achieved by converting the abc frame to their own dq components using a locked loop (PLL)[7]. Figure 1. shows a diagram of the PV system that connects the distribution system and the PCC through the VSC and the Ri + jwLi interface, where $\mathrm{w}$ is the angular frequency of the power system. The linear part impedance between the PCC and the network is $\mathrm{Rg}+\mathrm{jwLg}$. The RLC load is connected to the PCC. The investigation of the converter level control framework depends on an improved scientific model of the converter associated with the framework [8]. Two PI controllers are utilized to control the dc amount and the air conditioner side responsive power independently [9].

In traditional control conspires, the PWM-CSR has been worked with disconnected examples [10][11]. It demonstrates that dynamic damping can be promptly executed by methods for state variable criticism [12]. At long last, introduces a straightforward and minimal effort approach (it utilizes standard simple and computerized hardware) to accomplish close solidarity DPF [13]. Among other late advancements, space vector adjustment (SVM) has been appeared to have a high voltage increase, decreased exchanging recurrence, low line current consonant mutilation, and a clear usage on computerized frameworks [14]-[16].

The system model is being derived from initial assumption on grid voltage $\left(V_{b}\right)$ and generation bus active power $(\mathrm{Pi} \approx \mathrm{Ppv})$ as mentioned below.

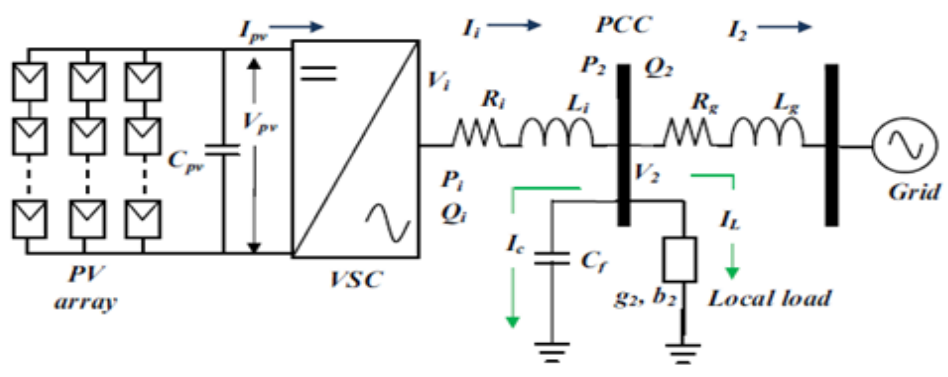

Figure 1. PV system interfaced with distribution system at PCC

$$
V_{2 Q}=V_{b Q}+R_{g} I_{2 Q}+X_{g} I_{2 D}
$$

where V_2 is voltage at PCC, I_2 is curren t from PCC to grid, $I_{i}$ is current from VSC to PCC, Q_i is reactive power generated at VSC. As PV is treated as a source of active power when connected in series, $Q_{i}$ is assumed to be zero. obtained as:

From the schematic diagram shown in Figure 3, the VSC dynamic model in abc reference frame is

$$
V_{i, a b c}=L_{i} \frac{d I_{i, a b c}}{d t}+R_{i} I_{i, a b c}+V_{2, a b c}
$$

where, $V_{i, a b c}=$ voltage at ac side of the VSC: $V_{2, a b c}=$ voltage at PCC; $V_{i, a b c}=$ instantaneous current at abc frame. After transformation of (5) from abc reference frame to dq reference frame, the VSC dynamic become: 


$$
\begin{aligned}
& \frac{d I_{i d}}{d t}=-\frac{R_{i}}{L_{i}} I_{i d}+\omega I_{i q}+\frac{V_{i d}-V_{2 d}}{L_{i}} \\
& \frac{d I_{i q}}{d t}=-\frac{R_{i}}{L_{i}} I_{i q}+\omega I_{i d}+\frac{V_{i q}-V_{2 q}}{L_{i}}
\end{aligned}
$$

where $V_{i, d q}=$ voltage at ac side of VSC; $V_{2, d q}=$ voltage at the PCC; $I_{i, d q}=$ Instantaneous current in d-q frame.

$$
\begin{aligned}
& V_{i d}=\frac{\sqrt{3}}{\sqrt[2]{2}} V_{p v}\left(m_{a} \cos \delta\right)=\frac{\sqrt{3}}{\sqrt[2]{2}} V_{p v} U_{d} \\
& V_{i q}=\frac{\sqrt{3}}{\sqrt[2]{2}} V_{p v}\left(m_{a} \sin \delta\right)=\frac{\sqrt{3}}{\sqrt[2]{2}} V_{p v} U_{q}
\end{aligned}
$$

where $V_{p v}=$ voltage at PV side of VSC; $m_{a}=\mathrm{PWM}$ modulation index $; \delta=$ phase angel for firing of IGBTs of VSC inverter. The power at PCC is obtained from the relationship:

$$
\begin{aligned}
& P_{2}=\frac{3}{2}\left(V_{2 d} I_{i d}+V_{2 q} I_{2 q}\right) \\
& Q_{2}=\frac{3}{2}\left(V_{2 q} I_{i d}+V_{2 q} I_{2 q}\right)
\end{aligned}
$$

At the PV side of the VSC, the dc link capacitor voltage shows another dynamic relation as (where switching losses is assumed to be neglected):

$$
C_{p v} \frac{d V_{p v}}{d t}=I_{p v}-\frac{P_{i}}{V_{p v}}
$$

which can be written as

$$
\begin{aligned}
\frac{d V_{p v}}{d t} & =\frac{1}{C_{p v} V_{P V}}\left(p_{p v}-P_{i}\right) \\
& =\frac{1}{C_{p v}}\left[I_{p v}-\frac{\sqrt{3}}{\sqrt[2]{2}}\left(I_{i d} U_{d}+I_{i q} U_{q}\right)\right]
\end{aligned}
$$

where PV power is calculated as

$$
P_{p v}=V_{P V} \times I_{p v}
$$

in (11), (12) and (16) are used to construct the dynamic model for the proposed VSC-based grid-integrated PV system. The operating frequency is attained during system dynamic operation by a droop control strategy as shown in (19).

$$
f-f_{0}=-R_{\text {droop }}\left(P_{i}-P_{p v}\right)
$$

where $f_{0}=$ nominal operating frequency.

\section{RESEARCH METHOD}

The PV system is integrated with the utility network via VSC. The purpose of the control is to maintain active $\left(P_{2}\right)$ and reactive $\left(Q_{2}\right)$ active energy in PCC. VSC output power can be controlled by PWM to VSC converter, which will provide power injection control to PCC. For the proposed system, the I-V control strategy is implemented with nonlinear FTFTSM controls. Therefore, PV side VSC voltage $\left(V_{p v}\right)$ and q axis current flowing from VSC to PCC $\left(I_{i q}\right)$ are considered as feedback signals to the controller. A small signal stability analysis of grid-connected VSC with PI control is outlined below. For PI control, basic current control strategy is being implemented.

\subsection{Small Signal Analysis with PI Control}

To evaluate stability behaviour, the system dynamics is represented in small signal terms as: 


$$
\begin{aligned}
& \frac{d \Delta I_{i d}(t)}{d t}=-\frac{R_{i}}{L_{i}} \Delta I_{i d}(t)+\omega \Delta I_{I q}(t)+\frac{\sqrt{3}}{\sqrt[2]{2}} \frac{\Delta V_{p v}(t)}{L_{i}} \Delta U_{d}(t)-\frac{\Delta V_{2 d}(t)}{L_{i}} \\
& \frac{d \Delta I_{i q}(t)}{d t}=-\frac{R_{i}}{L_{i}} \Delta I_{i q}(t)+\omega \Delta I_{I d}(t)+\frac{\sqrt{3}}{\sqrt[2]{2}} \frac{\Delta V_{p v}(t)}{L_{i}} \Delta U_{q}(t)-\frac{\Delta V_{2 q}(t)}{L_{i}}
\end{aligned}
$$

in (9) and (10) can be written in frequency domain as:

$$
\begin{aligned}
& \frac{1}{a_{1}}\left(s+\frac{R_{i}}{L_{i}}\right) \Delta I_{i d}(s)-\frac{\omega}{a_{1}} \Delta I_{i q}(s)+\frac{\Delta V_{2 d}(s)}{a_{1} L_{i}}=\Delta U_{d}(s) \\
& \frac{1}{a_{1}}\left(s+\frac{R_{i}}{L_{i}}\right) \Delta I_{i q}(s)-\frac{\omega}{a_{1}} \Delta I_{i d}(s)+\frac{\Delta V_{2 q}(s)}{a_{1} L_{i}}=\Delta U_{q}(s)
\end{aligned}
$$

where $a_{1}=\frac{\sqrt{3}}{\sqrt[2]{2}} \frac{\Delta V_{p v}(S)}{L_{i}}$ and the relationship expressed in (13) and (14) can be represented as:

$$
\left[\frac{1}{a_{1}}\left(s+\frac{R_{i}}{L_{i}}\right)-\frac{\omega}{a_{1}}\right]\left[\begin{array}{l}
\Delta I_{i d}(s) \\
\Delta I_{I q}(s)
\end{array}\right]+\left[\begin{array}{c}
\frac{\Delta V_{2 d}(t)}{a_{1} L_{i}} \\
\frac{\Delta V_{2 q}(t)}{a_{1} L_{i}}
\end{array}\right]=\left[\begin{array}{l}
\Delta U_{d}(s) \\
\Delta U_{q}(s)
\end{array}\right]
$$

or,

$$
\left[\begin{array}{ll}
G_{11} & G_{12} \\
G_{21} & G_{22}
\end{array}\right]\left[\begin{array}{l}
\Delta I_{i d}(s) \\
\Delta I_{i q}(s)
\end{array}\right]+\left[\begin{array}{l}
A_{1} \\
A_{2}
\end{array}\right]=\left[\begin{array}{l}
\Delta U_{d}(s) \\
\Delta U_{q}(s)
\end{array}\right]
$$

from the above equation, $\mathrm{d}$ axis current is directly related to control output as:

$$
G_{11} \Delta I_{i d}(s)+A_{1}=\Delta U_{d}(s)
$$

error from VSC input dc voltage is summed up through a gain with conventional current control loop for $\mathrm{d}$ axis current error is taken into account. Through proportional $\left(K_{p 1}\right.$ and $\left.K_{p 2}\right)$ and integral $\left(K_{i 1}\right.$ and $\left.K_{i 2}\right)$ gain the PI scheme is implemented as shown in Figure 4.

From the above schematic, relation between feedback error and the response can be established as:

$$
\left(\Delta I^{*}{ }_{i d}(s)-\Delta I_{i d}(s)\right)\left[K_{p 1}+\frac{K_{i 1}}{s}\right]+K_{p v}\left(\Delta V_{p v}^{*}(s)-\Delta V_{p v}(s)\right)=\Delta U_{d}(s)
$$

substituting $\Delta U_{d}(s)$ from (21) we can rewrite the above equation as:

$$
\text { Where } G_{P 1}=\left[K_{p 1}+\frac{K_{i 1}}{S}\right]
$$

A closed loop system is achieved in (19), where dc voltage error is potential to put negligible deviation to PCC bus due to the decoupling through VSC. Hence, by neglecting dc voltage error, the system in (19) will represent a SISO system whose stability is determined by the pole.

\subsection{I-V Control Strategy with Adaptive FFTSM Control.}

Basically, PI-based VSC control approach is one of the conventional one. Despite having the advantages like simplified construction, steady-state error, PI-based controller is deficient in high overshoot during sudden disturbances, fragile nature to controller gains, sluggish response and above all performance deterioration during change in operating conditions. To overcome difficulties associated with PI control, the concept of nonlinear control has been introduced. In present work, an ordinary terminal sliding mode (TSM) control is thus compared with proposed FTFTSM approach. To implement nonlinear control for VSC, the system dynamic model is described in terms of state space model as mention below.

Where $x$ is the state vector, $u$ is the input vector and $y$ is the output vector to be controlled. From (3), (4) and (9) it is clear that system dynamics depend on three state variables, $I_{i d}, I_{i q}$ and $V_{p v}$ respectively. Thus, the state vector and input vector are constructed as in (20) and (21). 
$x=\left[\begin{array}{l}x_{1} \\ x_{2} \\ x_{3}\end{array}\right]=\left[\begin{array}{l}I_{i d} \\ I_{i q} \\ V_{p v}\end{array}\right]$

$u=\left[\begin{array}{l}u_{d} \\ u_{q}\end{array}\right]$

From the three dynamic equations the state space functions are obtained as:

$f(x)=\left[\begin{array}{c}-\frac{R_{i}}{L_{i}} x_{1}+\omega x_{2}-\frac{V_{2 d}}{L_{i}} \\ -\frac{R_{i}}{L_{i}} x_{2}+\omega x_{1}-\frac{V_{2 q}}{L_{i}} \\ \frac{I_{p v}}{C_{p v}}\end{array}\right]$

$g(x)=\left[\begin{array}{cc}\frac{\sqrt{3}}{\sqrt[2]{2}} \frac{x_{3}}{L_{i}} & 0 \\ 0 & \frac{\sqrt{3}}{\sqrt[2]{2}} \frac{x_{3}}{L_{i}} \\ -\frac{\sqrt{3}}{\sqrt[2]{2}} x_{1} & -\frac{\sqrt{3}}{\sqrt[2]{2}} x_{2}\end{array}\right]$

Hence the output smooth scalar function is defined as in (24).

$h(x)=\left[\begin{array}{l}x_{2} \\ x_{3}\end{array}\right]=\left[\begin{array}{l}I_{i q} \\ V_{p v}\end{array}\right]$

\section{RESULTS AND ANALYSIS}

A $100 \mathrm{~kW}, 230 \mathrm{~V}$ PV system integrated with utility grid is simulated in MATLAB/SIMULINK for performance validation of proposed model described in Figure 2.

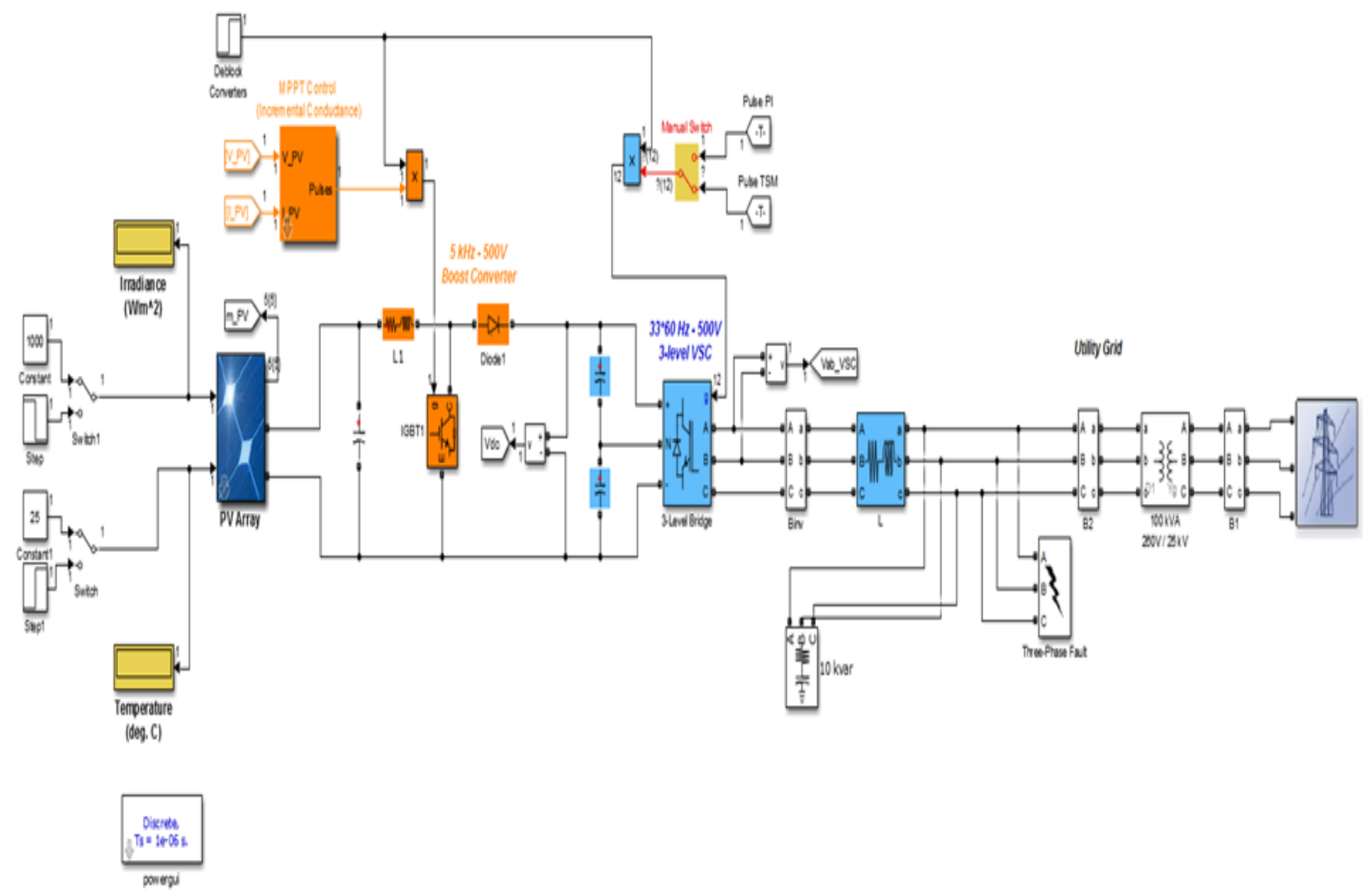

Figure 2. Simulation verification model of PV integrated grid system 


\subsection{Performance During Fault}

The performance of the proposed nonlinear control is evaluated, compared PI control. The proposed control technique is robust, effective in terms of dynamic fault response as well as uncertain parametric changes. The dynamic stability condition is validated by finite time error convergence attained.

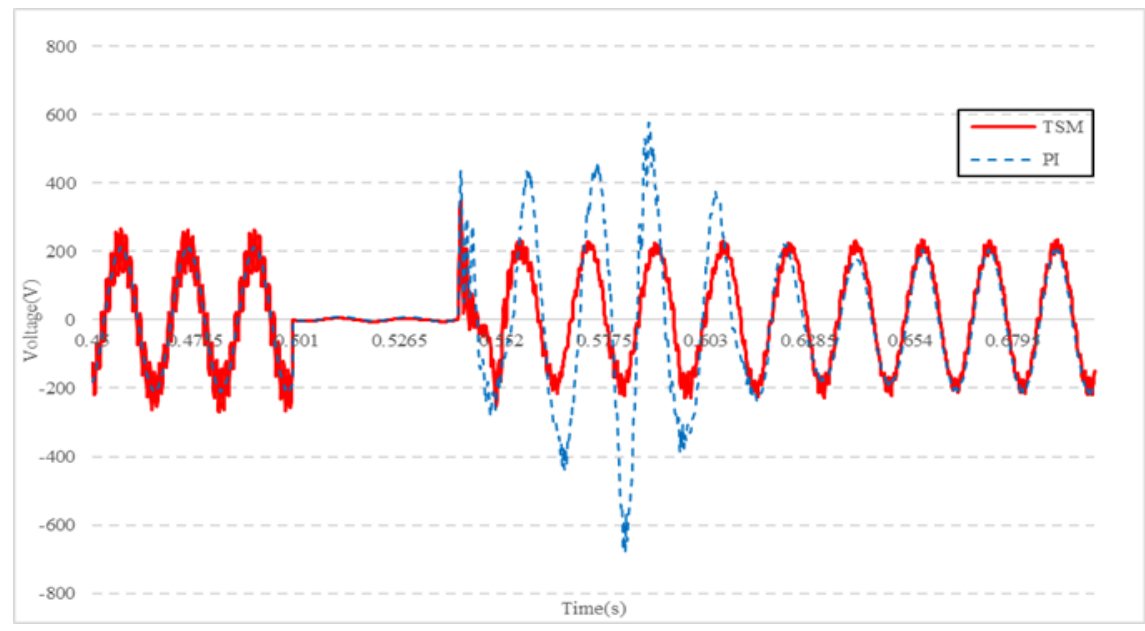

Figure 3. Voltage at PCC

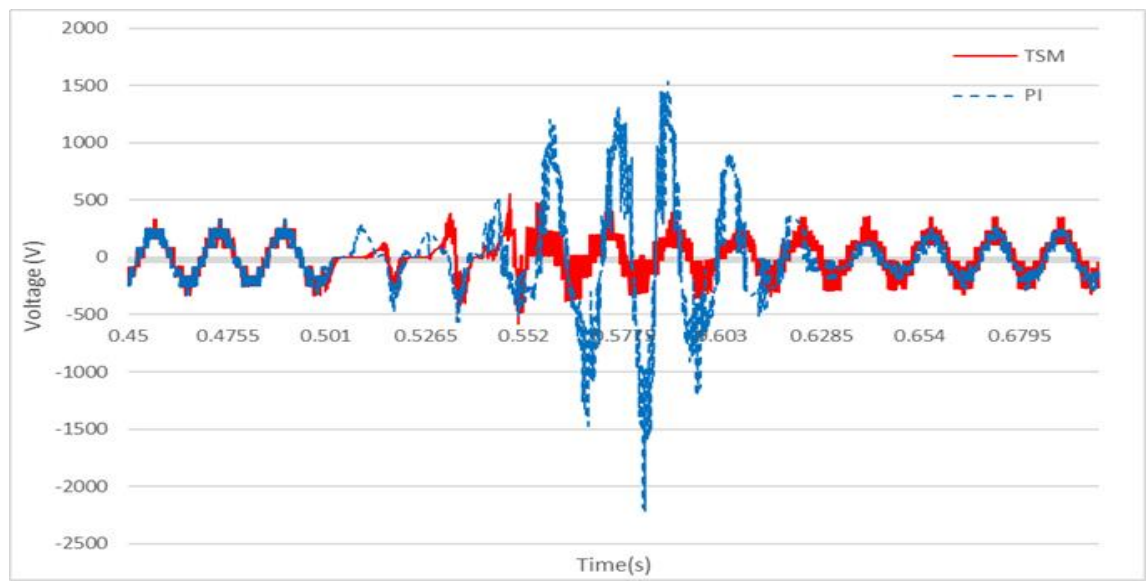

Figure 4. Inverter Voltage

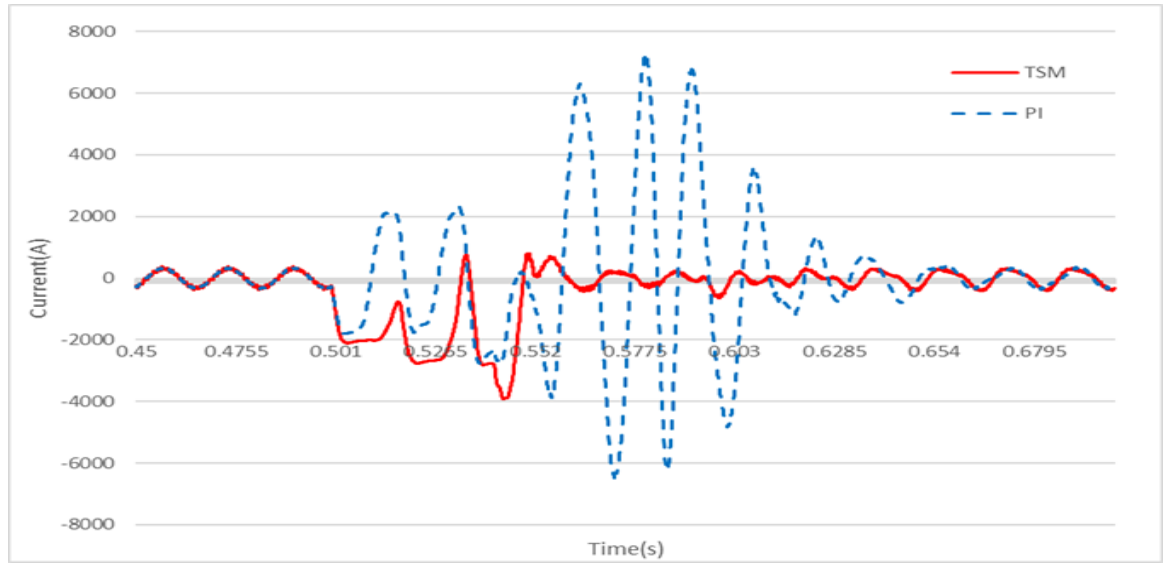

Figure 5. Inverter current 


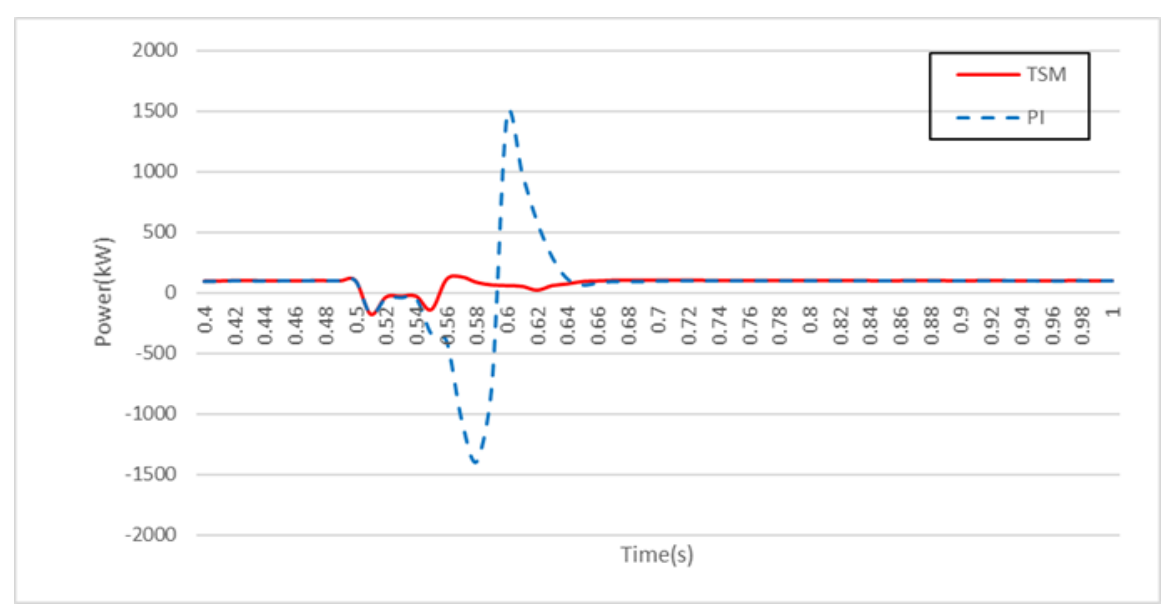

Figure 6. Active power at PCC

The system is subjected to three-phase fault at the grid for 5 cycles at time $=0.5 \mathrm{~s}$ as shown in Figure 7. The p.u set point values of active and reactive power at the PCC, prior to the fault are $\mathrm{P} * 2=1.026$, $Q * 2=-0.2016$. Various system parameters including voltage, current, active and reactive power responses during fault and post-fault recovery are shown in Figire 7 in per unit (p.u). the performance of the proposed controller is certainly better with a settling time $0.3 \mathrm{~s}$ as compared to PI controller which takes $2 \mathrm{~s}$ to regain stability with oscillating characteristics. From the test case fault recovery time and improved damping in comparison with both the PI controllers.

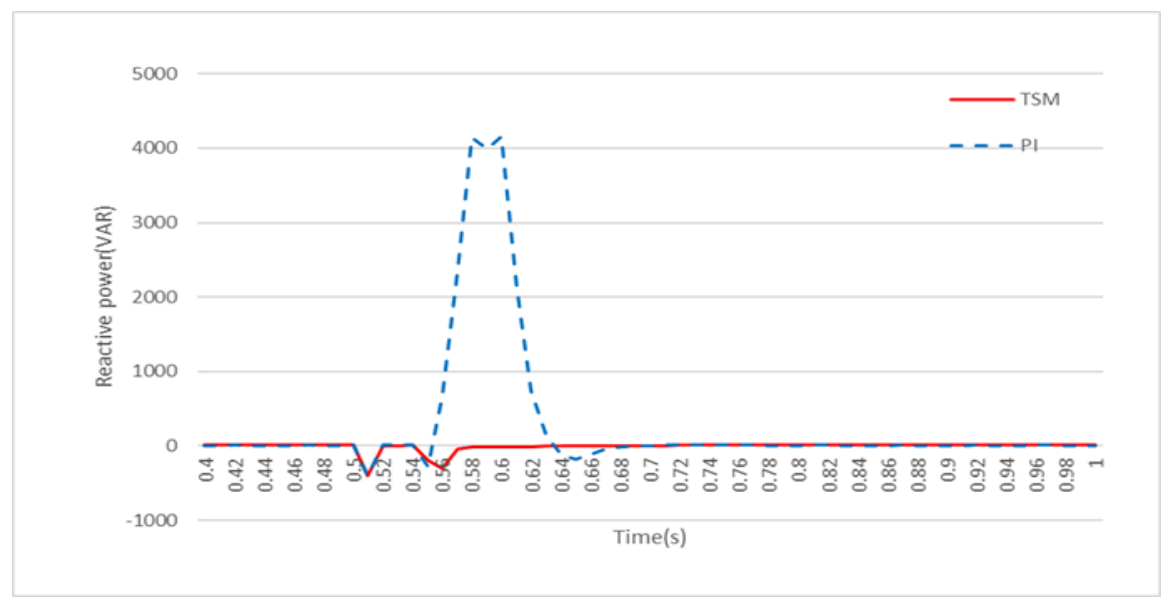

Figure 7. Reactive power at PCC

\section{CONCLUSION}

In this paper, a new nonlinear control strategy for a three-phase grid connected PV generation system is proposed. The VSC converter interface between the PV array and the grid is modelled in a stationary phase frame using $\mathrm{d}-\mathrm{q}$ axis current component at PCC, and dc voltage as dynamic variables. The stability theorem has been developed in the paper using the reactive power and dc link voltage errors. Further the instantaneous active and reactive power waveforms are not influenced by the PLL dynamics in the beginning of the control design. The simulation results of the PV system model using MATLAB script/Simulink, environment shows clearly that the proposed non-linear controller provides control with less settling time, overshoot, and less oscillatory response compared with PI control strategies. Future work will be established for grid faults (unsymmetrical) and other grid operational events, where the control design will be further modified into a more effective by sequence components consideration. 


\section{ACKNOWLEDGEMENTS}

The author and researchers sincerely thank IRMI, 600-IRMI/DANA 5/3/LESTARI (0169/2016), and UiTM for providing lab facility and the fund to conduct this research smoothly.

\section{REFERENCES}

[1] N. G. Hingoranl, L. Gyugyi, and M. E. El-Hawary, Understanding FACTS: Concepts and technology of flexible ac transmission systems. 1999.

[2] I. Papič, "Power quality improvement using distribution static compensator with energy storage system," in Proceedings of International Conference on Harmonics and Quality of Power, ICHQP, 2000, vol. 3, pp. 916-920.

[3] Y. Ye, M. Kazerani, and V. H. Quintana, "A novel modeling and control method for three-phase PWM converters," 2001 IEEE 32nd Annu. Power Electron. Spec. Conf. (IEEE Cat. No.01CH37230), vol. 1, pp. 102-107, 2001.

[4] P. W. Lehn and M. R. Irvani, "Discrete time modeling and control of the voltage source converter for improved disturbance rejection," IEEE Trans. Power Electron., vol. 14, no. 6, pp. 1028-1036, 1999.

[5] P. W. Lehn and M. R. Iravani, "Experimental evaluation of STATCOM closed loop dynamics," IEEE Trans. Power Deliv., vol. 13, no. 4, pp. 1378-1384, 1998.

[6] D.-C. L. D.-C. Lee, K.-D. L. K.-D. Lee, and G.-M. L. G.-M. Lee, "Voltage control of PWM converters using feedback linearization," Conf. Rec. 1998 IEEE Ind. Appl. Conf. Thirty-Third IAS Annu. Meet. (Cat. No.98CH36242), vol. 2, 1998.

[7] S. Dhar and P. K. Dash, "A Finite Time Fast Terminal Sliding Mode I-V Control of Grid-Connected PV Array," J. Control. Autom. Electr. Syst., vol. 26, no. 3, pp. 314-335, 2015.

[8] C. Schauder and H. Mehta, "Vector analysis and control of advanced static var compensators," Conference Publication no. 345 of the IEE Fifth International Conference on AC and DC Power Transmission, September 1991, pp. 266-272.

[9] R. Itoh, and K. Ishizaka, "Series Connected PWM GTO Current/Source Converter With Symmetrical Phase Angle Control”, IEE Proceedings B (Electric Power Applications), vol. 137, no. 4, July 1990, pp. 205-212.

[10] C. Namuduri and P. Sen, "Optimal pulse width modulation for current source inverters," IEEE Trans. Ind. Applicat., vol. IA-22, pp. 1052-1072, Nov./Dec. 1986.

[11] H. Karshenas, H. Kojori, and S. Dewan, "Generalized techniques of selective harmonic elimination and current control in current source inverters/converters, ” IEEE Trans. Power Electron., vol. 10, pp. 566573, Sept. 1995.

[12] Y. Sato and T. Kataoka, “A current type PWM rectifier with active damping function," IEEE Trans. Ind. Applicat., vol. 32, pp. 553-541, May/June 1996.

[13] N. Zargari and G. Joos, "An on-line operated near unity power factor 'PWM rectifier with minimum control requirements," in Conf. Rec. IEEE IECON'94, 1994, pp. 593-598.

[14] J. Holtz, "Pulsewidth modulation-A survey," IEEE Trans. Ind. Electron., vol. 39, pp. 410-420, Oct. 1992.

[15] V. Vlatkovic and D. Borojevic, "Digital-signal-processor-based control of three-phase space vector modulated converters," IEEE Trans. Ind. Electron., vol. 41, pp. 326-332, June 1994.

[16] J. Espinoza and G. Jo'os, "Current-source converter on-line pattern generator switching frequency minimization,” IEEE Trans. Ind. Electron., vol. 44, pp. 198-206, Apr. 1997. 